\title{
Alguns aspectos da astrologia em Kepler
}

\section{Some aspects of Kepler's astrology}

\author{
LUANA PAULA GOULART DE MENEZES \\ Universidade Estadual de Maringá | UEM \\ MICHEL CORCI BATISTA \\ Universidade Tecnológica Federal do Paraná | UTFPR \\ DANIEL GARDELLI \\ Universidade Estadual de Maringá | UEM
}

\begin{abstract}
RESUMO Neste trabalho apresentaremos um pequeno estudo sobre a astrologia de Kepler e algumas reflexões sobre a prática em suas concepções. O escrito que norteou nossa pesquisa foi De fundamentis astrologiae certioribus (1602), um trabalho em que temos uma preocupação com os fundamentos da astrologia, além das previsões para o referido ano. Nossa análise se voltou, principalmente, nas características dos planetas que nos levou a iniciar uma reflexão sobre o papel da luz. A partir desse estudo acreditamos ser possível, de fato, atribuir uma fundamental importância da astrologia em sua cosmologia.
\end{abstract}

Palavras-chave Johannes Kepler - astrologia - características dos planetas - luz

\begin{abstract}
In this work we will present a small study on Kepler's astrology and some reflections on the practice in his conceptions. The writing that guided our research was De fundamentis astrologiae certioribus (1602), a work in which we are concerned with the fundamentals of astrology, in addition to the forecasts for that year. Our analysis focused mainly on the characteristics of the planets that led us to start a reflection on the role of light. From this study we believe it is possible, in fact, to attribute a fundamental importance of astrology in its cosmology.
\end{abstract}

Keywords Johannes Kepler - astrology - characteristics of the planets - light

\section{Introdução}

0 título deste estudo sugere duas interpretações: a palavra "aspectos" pode sugerir que iremos tratar um ponto de vista ou um conhecedor da astrologia pensará que escreveremos sobre os aspectos astrológicos. Nossa intenção, todavia, é de fato apresentar um ponto de vista e que ocasionou em abordar, entre outros assuntos, os aspectos. Desse modo, com objetivo de abrir algumas passagens dos escritos de Kepler, para uma melhor interpretação convém apresentarmos a seguir algumas considerações.

Tetrabiblos é título de um dos trabalhos de Ptolomeu escrito no século Il d. C. e é considerado um livro fundamental para a astrologia, vejamos um trecho desse escrito: 
Das ciências que fornecem prognóstico pelo emprego da astronomia, ó Syros, duas têm mais importância e autoridade. Por meio de uma delas, primeira em ordem e poder, compreendemos as configurações usuais dos movimentos do Sol, da Lua e dos astros em relação uns com os outros e com a Terra. Por meio da segunda, investigamos as transformações concretizadas no ambiente terrestre e na atmosfera, através da particularidade natural das próprias configurações ${ }^{1}$.

Embora Ptolomeu não use o termo "astrologia" essa passagem é entendida como distinção entre astronomia e astrologia, sendo que a segunda depende da primeira, porém, a astronomia sem astrologia não tem tanta utilidade ${ }^{2}$. Apesar de tal dependência descrita, a astrologia é uma prática que desapareceu do conhecimento legítimo e os detalhes deste desaparecimento ainda não estão totalmente esclarecidos, todavia, há que se admitir que existe uma grande tendência das pessoas em acreditar nos seus princípios. Depois de perder força em torno do século XVIII, a astrologia tem ganhado novamente cenário de popularidade desde a década de 1930. Em uma tentativa de mudar isso, segundo Paul Thagard, "Bart Bok, Lawrence Jerome e Paul Kurtz elaboraram em 1975 uma declaração atacando a astrologia; a declaração foi assinada por 192 cientistas de renome, incluindo 19 ganhadores do prêmio Nobel"쯔 . 0 fato é que, apesar dessas críticas, é comum que muitas pessoas saibam ao menos o seu signo do zodíaco ou já tenham consultado seus horóscopos na mídia, ainda que, como escreve Thagard, não é justo reduzir a astrologia aos horóscopos diários que "lidam apenas com signos solares, ao passo que um horóscopo completo faz referência às 'influências' também da Lua e dos Planetas, enquanto também discute 0 sinal ascendente e outros assuntos" .

Em contraste, no ambiente científico se abomina a astrologia e é para alguns inacreditável que estudiosos como Johannes Kepler (1571-1630) e Galileu Galilei (1564-1642) a praticavam5 . Sem o intuito de discutir a prática como um crime, iniciamos um estudo de algumas características da astrologia em Kepler de modo a iniciar uma maior compreensão e quem sabe provocar reflexões sobre como o tema é tratado.

Com tais considerações, em Field encontramos vários esclarecimentos sobre a astrologia de Kepler bem como um escrito traduzido do Latim (De fundamentis astrologiae certioribus, de 1602) em que é possível verificar suas concepções sobre a astrologia naquele momento ${ }^{\underline{6}}$. Uma das primeiras dúvidas é que tipo de astrologia Kepler praticava. Sendo assim, deixamos claro que existe um conceito de astrologia chamada "baixa" relacionada com misticismo, adivinhação, com características folclóricas e uma "alta" que podemos associar aquela praticada por Kepler preocupada com questões de grande escala como clima. Tal distinção não é nítida e:

em parte, atravessa a divisão diferente que KEPLER e seus contemporâneos fizeram entre a astrologia natural (uma parte da física sublunar, por se preocupar com os efeitos dos planetas e das estrelas nos corpos terrestres, por exemplo, formando minerais na Terra) e astrologia judicial (que estava preocupada com coisas como escolher um dia auspicioso para assinar um tratado, ou quebrar um)? .

Kepler foi mathematicus imperial e entre suas atividades estava incluída a astrologia, sendo que esta fazia parte

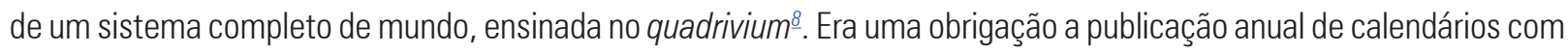
previsões astrológicas e, além disso "tinha a vantagem de uma remuneração extra de vinte florins por calendário, ganho muito importante e útil a Kepler, tendo em vista que seu salário era de apenas cento e cinquenta florins por ano"․․ Em outubro de 1594, aparece o calendário de 1595, primeiro de muitos outros, e do qual Ihe gerou muito sucesso, visto que acertou a previsão de um inverno severo, avanços militares turcos e levantes camponeses ${ }^{10}$.

Boner escreve que a negligência da astrologia de Kepler foi duplamente lamentável, pois foi um componente central de seu esquema harmônico, bem como um meio primário do qual descreve sua concepção de anima. Ele continua escrevendo que a maioria dos trabalhos considera comparativamente a astrologia em seu quadro de pensamento astronômico e poucos consideram suas implicações filosóficas e que de modo evidente Kepler considerava a astrologia um componente integral da sua cosmologia, acompanhando "suas análises astrológicas com discussões sobre assuntos como a composição e compreensibilidade do cosmos"11. 
No Brasil existem ainda poucos estudos sobre a obra e vida de Kepler, por este motivo boa parte de nossas referências são pesquisas de outros países. No site da Bayerische Akademie der Wissenschaften existe uma série de trabalhos do astrônomo divididos em volumes, inclusive sobre astrologia. Ao abrir Manuscripta Astrologica, Manuscripta Pneumatica ${ }^{12}$, publicado em 2009, podemos encontrar trabalhos astrológicos em que é possível notar um complexo método de elaboração por intermédio de símbolos e cálculos. Como são muitos horóscopos e outros feitos, uma primeira curiosidade que podemos ter é como Kepler lidava com a atividade. Um trecho de uma carta para Herwart em 1599 Kepler nos revela um sentimento que já suspeitávamos: desabafa dizendo que escrever "natividade" e "calendário" é um trabalho escravo irritante, mas necessário para ele manter seu salário e residência ${ }^{13}$. Neste período, Kepler estava em uma situação não muito fácil, uma vez que protestantes de Graz (cidade onde morava desde 1594) haviam sido expulsos e ele não tinha nenhum trabalho em vista ${ }^{14}$. Kepler se esforça para renovar a Astrologia, mas, por outro lado, nos parece preocupado dirigindo especialmente a D. Philippum Fefelium (que faz severas críticas à superstição), que não deve jogar fora o bebê com a água do banho e prejudicar a profissão como podemos ver abaixo na capa de Tertius Interveniens (1610) ${ }^{15}$. Nesse trabalho, Kepler propõe uma discussão entre personagens com a intenção de defender que uma astrologia sólida é possível.

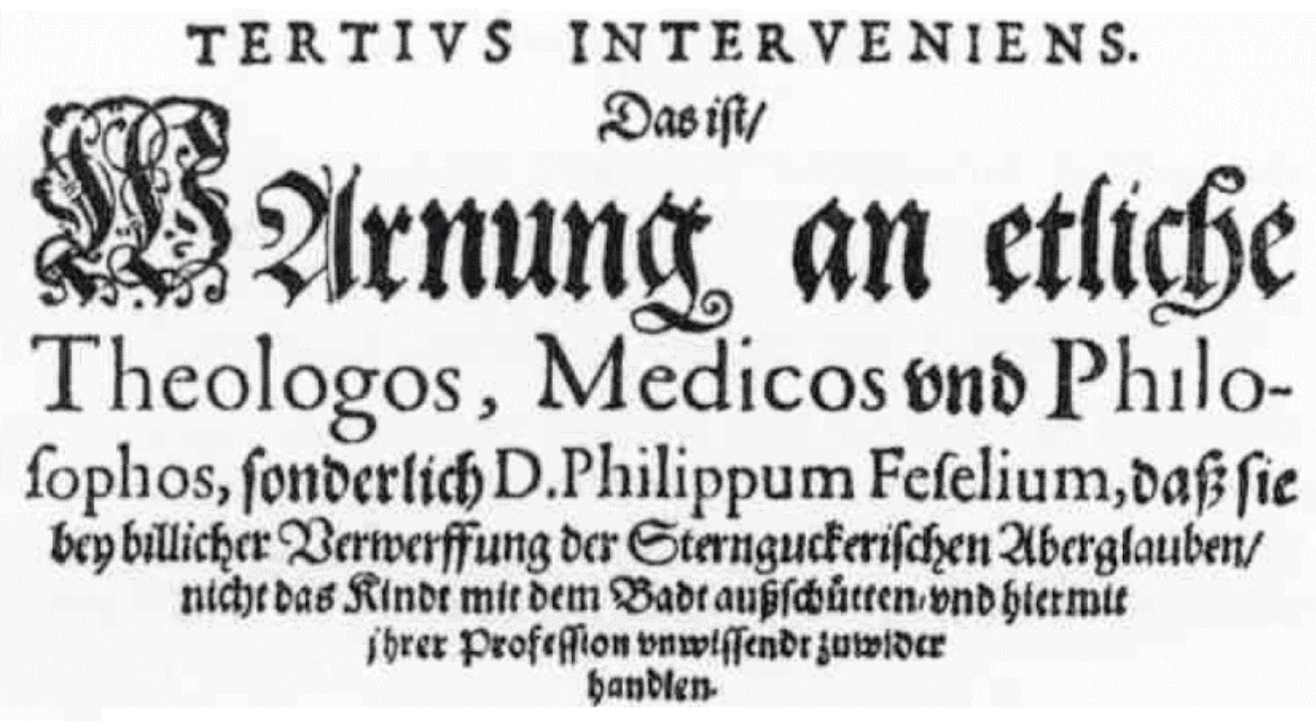

Figura 1 - Tertius interveniens.

Fonte: KEPLER (1602/1611, v. 4, p. 148)

Para entendermos um pouco melhor sobre sua prática nós passamos a discutir agora sobre um dos conceitos da astrologia: os aspectos. Este conceito aparece com Ptolomeu:

As passagens das estrelas fixas e errantes produzem a maioria das manifestações do ambiente - calor, vento, neve-, por meio das quais as coisas sobre a Terra também são organizadas da maneira conveniente. Além disso, as configurações dos astros uns em relação aos outros - aspectos - operam muitas e complexas transformações, sendo as distribuições de seus efeitos de algum modo reunidas e misturadas ${ }^{\underline{16}}$.

Por enquanto, guardamos tal trecho e observemos que para Aristóteles existem tipos de almas. Na mesma perspectiva, Kepler também cita almas sendo que um desses tipos era a alma da Terra, mais animista do que o Sol, a alma sublunar era uma espécie de "chama alimentada pela respiração, como a do fogo ou faíscas"117 sendo que "esta alma estava enraizada no centro da Terra como a alma humana está no coração" $\underline{18}$. Por outro lado, a alma do Sol que 
faltava as capacidades cognitivas, era dotada de uma faculdade motora responsável pelo movimento dos planetas. Desse modo, Kepler explica que o Sol emitia com a luz uma virtus motrix em linhas perpendiculares à sua superfície e que "este virtus girou como um vórtice muito rápido, chegando a todas as partes em momentos iguais" 19 . Assim como a luz para Kepler, este a virtus motrix que emanava do Sol diminuía sua intensidade com o aumento da distância ao Sol e consequentemente temos menos impacto em planetas distantes. Neste contexto Kepler acreditava que as configurações angulares dos planetas moviam a faculdade espiritual da Terra organizadas em ordem de maior a menor impacto potencial e assim como Ptolomeu fez em Tetrabiblos usou o termo aspectos para essas configurações. De modo mais específico aspecto pode ser expresso como "o ângulo em que dois raios de luz, descendo cada um de seu próprio planeta, se encontrou, no centro da alma sublunar. Este ângulo corresponde a um arco marcado a partir do restante do círculo do zodíaco"르․

A partir da visão de Kepler exposta por Boner passamos a estudar seus fundamentos e previsões do escrito De fundamentis astrologiae certioribus (1602). Em Field encontramos uma discussão dão indícios das prováveis intenções de Kepler: depois de publicar seu calendário de 1698, seu professor Maestlin escreveu uma carta (perdida) para Kepler criticando a sua dureza, que respondeu que não rejeitou a astrologia e que queria reformá-la. Maestlin responde que apenas achava mais adequado que tais argumentos fossem usados como questão de debate e não havia suposto que ele tinha rejeitado a astrologia como um todo. Todavia, tal troca de correspondências parece não intervir na publicação para 0 ano 1599, mas talvez sim na de 1602, em que Kepler procura justificar suas próprias opiniões e não se preocupa em refutar opiniões dos outros. É importante ressaltar que como escreve Field este trabalho não é escrito como parte de uma controvérsia como foi Tertivs Interveniens (1610).

Para continuar nossa discussão, passamos agora a descrever alguns pontos de algumas das suas 75 teses do escrito. Como fez parte do nosso estudo procuramos algumas relações sobre os aspectos. Iniciemos pela sua tese XXXVII em que Kepler afirma que assim como não existem mais do que cinco poliedros regulares em geometria, não pode haver mais que oito relações harmônicas que surgem em comparação com figuras planas regulares e que ele, se Deus quiser, mostrará em seu livro sobre harmônicos²1. Na sua tese XXXVIII ele explica melhor que assim como existem oito razões que determinam os movimentos, e a ação dos Céus na Terra, os ângulos são traduzidos pelas relações harmônicas. Estes aspectos são normalmente conhecidos como: Conjunção, Oposição, Trígono, Quadratura e Sextil, mas sua experiência indica mais três: Ouintil, Sesquiquadratura e Biquintil que seriam ângulos de $72^{\circ}, 144^{\circ}$ e $135^{\circ}$, respectivamente. A experiência dita são as "previsões" que deram certo.

Vejamos um trecho de como tais aspectos são tratados nas previsões para o mês de janeiro de 1602:

[Tese LII - Janeiro]: [...]Em 4 de janeiro, a conjunção do Sol e Mercúrio trará neve ou ventos, de acordo com a disposição geral da Terra. Por volta de 10 e 11 de janeiro, há seis aspectos muito poderosos. Calor puro e chuva se misturavam à neve. No final nada pode ser previsto a partir de aspectos antigos, mas a partir dos novos prevemos que o quintil de Júpiter e Vênus fará o dia 21 arejado e quente, tanto quanto o inverno permite. O dia 24, com Saturno e o Sol no Quintil, será frio, com neve ou chuva. O dia 28, com Marte e o Sol na Sesquiquadratura, será rigoroso, com fortes ventos ferozes e trará neve. Então aqueles que estão preocupados em testar a validade dos novos Aspectos devem investigar estes dias. $\underline{22}$

Kepler admite que podem ocorrer infinitos aspectos, todavia se os aspectos atuam com infinitos outros a teoria seria inútil, além disso, pensa não haver mais que oito consonâncias em uma corda e deste modo, possuem iguais princípios arquetípicos ${ }^{23}$ construídos por restrições claramente definidas. Tais princípios foram produzidos com régua e compasso em um círculo. No caso da quadratura temos a separação de dois planetas pelo círculo com quatro pontos equidistantes. 0 número do ângulo e lados não importava tanto quanto a capacidade de ser racional. Desse modo, descarta, por exemplo o heptágono, polígono que não podemos inscrever em um círculo com régua e compasso, a não ser de modo aproximado. De acordo com Bonner "para Kepler, o estudo da astrologia convocou o mesmo conjunto de princípios que encontrou no coração da sua epistemologia", sendo que unificado com os arquétipos, o cosmos de Kepler tem como base um desenho metafísico divino 24 . 


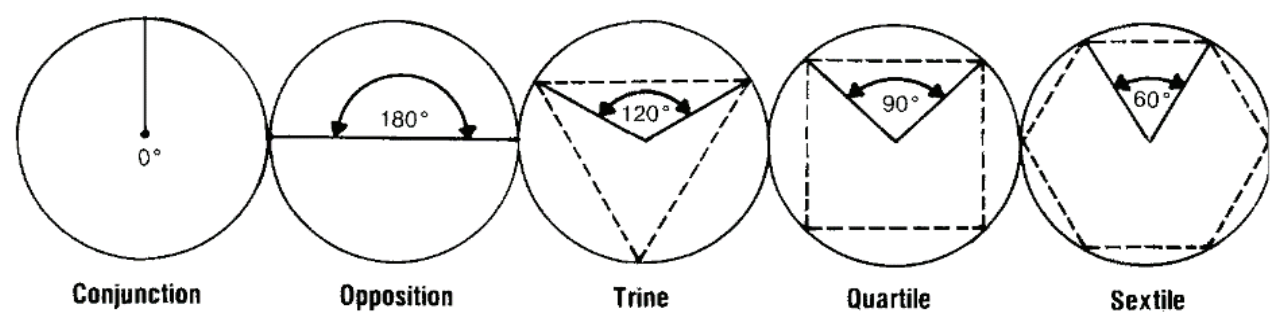

THE TRADITIONAL ASTROLOGICAL ASPECTS

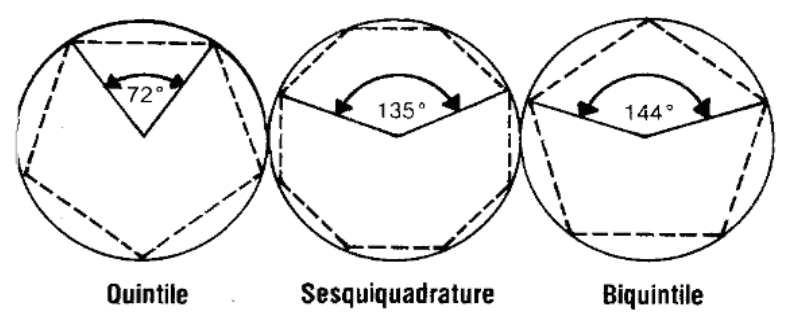

KEPLER'S NEW ASPECTS

Figura 2 - Aspectos tradicionais e novos.

Fonte: BRACKENRIDGE (1982, p. 141) $)$.

\section{As características dos planetas}

Na sua Tese XXI Kepler escreve sobre as estrelas que não criam, mas prestam assistência, sendo assim um instrumento: 1) Por intermédio do poder de umidificação e 2) Através do poder de aquecimento. Estes poderes que elas possuem e exercem por intermédio do benefício da luz. Assim, quando ela é emitida de forma direta aquece e quando é refletida umedece.

Aquecimento e umedecimento são duas faculdades de acordo com a tese XXII e possuem três variáveis: Excesso, Moderação e Deficiência (ou uma espécie de falta para ocorrer uma completude). A partir daí, há faculdades que podem ser solitárias, isto é, aquecimento: em excesso, moderação ou enfraquecido e umidificação: em excesso, moderação ou enfraquecida. Isto é, seis variações. Quando combinadas duas a duas temos combinações que somadas com as outras 6 dão o resultado de 15, sendo estas:

1. Aquecimento em excesso;

2. Aquecimento em moderação;

3. Aquecimento em falta;

4. Umidificação em excesso;

5. Umidificação em moderação;

6. Umidificação em falta;

7. Excesso em aquecimento + excesso em umidificação; 
8. Excesso em aquecimento + moderação da umidificação;

9. Excesso em aquecimento + falta de umidificação;

10. Média em aquecimento + excesso em umidificação;

11. Média em aquecimento + moderação da umidificação;

12. Média em aquecimento + falta de umidificação;

13. Falta de aquecimento + excesso em umidificação;

14. Falta de aquecimento + moderação da umidificação;

15. Falta de aquecimento + falta de umidificação $0^{\frac{26}{}}$.

Depois disso passa argumentar quais devem ser mantidas e quais rejeitadas. Na sua tese XXIII começa rejeitando 1, 3, 4 e 6, pois não é razoável que qualquer excesso ou falta exista sem qualquer propriedade compensadora. Há moderação no calor, atribuído ao Sol no qual a luz é intrínseca e na umidificação atribuída à Lua que possui luz emprestada do Sol e das estrelas.

Na tese XXIV explica que não é possível o acúmulo de dois excessos ou duas faltas. Uma vez que excessos são um pouco antinaturais se eles não têm uma falta para equilibrar. Nenhum planeta foi feito para receber excesso e defeito na mesma faculdade. Logo, eliminamos 7, 9, 13 e 15. Continua Kepler que existe a mesma proporção entre 0 excesso de aquecimento com moderação de umidade e a moderação de aquecimento com a falta de umidade, o mesmo vale para a falta de aquecimento com moderação da umidade que equivale ao aquecimento moderado e 0 excesso de umidade. Ainda que Kepler não escreve que tais combinações são quantidades, é possível entender as combinações citadas por meio da atribuição de valores para cada nível de aquecimento e umidade como mostra a tabela abaixo:

Tabela 1- Nossa interpretação do Aquecimento e Umidade

\begin{tabular}{l|c|c|c} 
& Falta & Moderação & Exceso \\
Aquecimento & 1 & 2 & 3 \\
\hline Umidade & -1 & -2 & -3 \\
\hline
\end{tabular}

Fonte: Os autores.

Então:

Excesso de aquecimento + moderação de umidade

Moderação de aquecimento + falta de umidade .

Do mesmo modo:

Falta de aquecimento + moderação da umidade

Aquecimento moderado + excesso de umidade

Segundo Kepler, como consequência sobram 5 variações que são: "três simples", "duas duplas" e "uma com três". Isto nos parece confuso. Ele ainda justifica o número cinco (apesar que outras causas podem ser envolvidas), já que existem apenas cinco planetas, dois inferiores e três superiores: "nada poderia ser mais apropriado do que a distribuição dessas combinações de faculdades entre os planetas da maneira mostrada na minha figura" $\underline{\text { 27. }}$. 


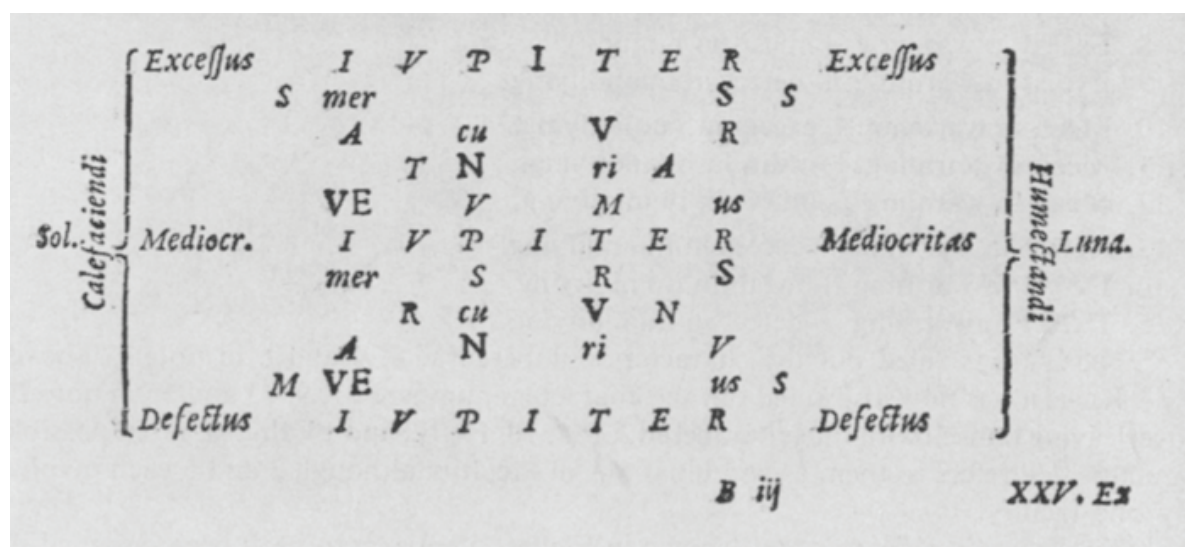

Figura 3- De fundamentis (tese XXIV). Fonte: Fotografia (British Library), disponível em Field (1984, p. 240).

Reproduzimos a figura, destacando os planetas com variações simples e duplas abaixo.

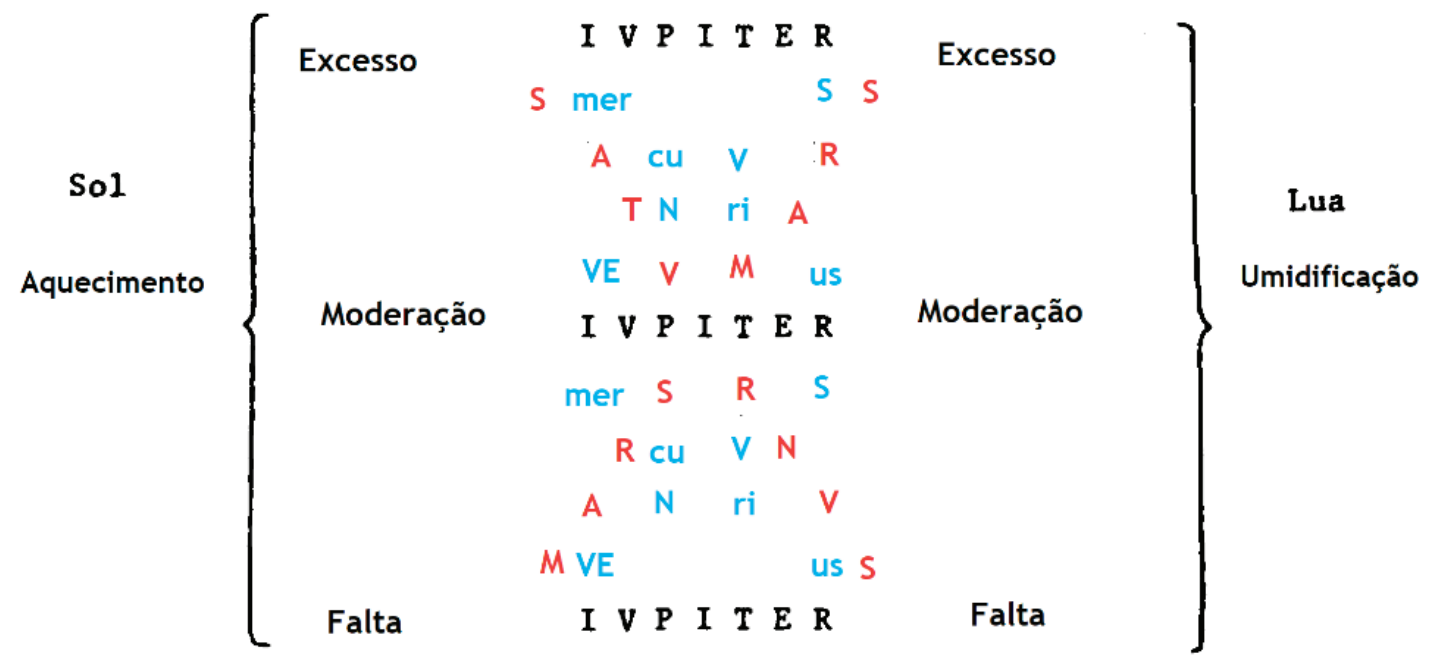

Figura 4 - Nossa reprodução da Figura 3- De fundamentis (tese XXIV). Fonte: Os autores.

Para fazermos algumas considerações nos lembremos que Ptolomeu coloca o centro na Terra e organiza os planetas de acordo com os períodos sobre a Terra. Desse modo, a ordem fica: Lua, Mercúrio, Vênus, Sol, Marte, Júpiter e Saturno. Kepler adota o sistema de Copérnico, organizando na ordem: Sol, Mercúrio, Vênus, Terra e Lua, Marte, Júpiter e Saturno. Pelo "uso bem-sucedido" as características de Marte (quente e seco) e Vênus (quente e úmido) foram bem estabelecidas. Para Ptolomeu, a natureza de Marte é principalmente para secar e para queimar, em conformidade com a sua cor de fogo e em razão de sua proximidade com o Sol, já que a esfera do Sol fica logo abaixo dele. Júpiter tem uma força moderada já que seu movimento ocorre entre a influência de refrigeração de Saturno e o poder de queima de Marte. Saturno tem qualidade principalmente para esfriar e moderadamente secar, provavelmente porque ele está mais afastado tanto do calor do sol e as exalações úmidas da Terra. Vênus é análogo a Júpiter, porém, age de forma oposta, pois aquece moderadamente pela proximidade com o Sol e principalmente umedece por conta da sua luz própria e das exalações úmidas da Terra. Mercúrio seca em alguns momentos e também absorve umidade por conta da sua posição acima da esfera da Lua e muda de forma rápida de uma hora da outra pela velocidade do seu próprio movimento nas proximidades do Soli $\stackrel{10}{ }$. 
Como a experiência aponta marte como seco e quente, nos parecia que havia erro no mapa de Kepler, o que de fato foi constatado quando acessamos uma nota que diz sobre uma anotação no próprio livro de Kepler que corrige a ordem de Marte e Saturno, isto é, onde se lê marte, na verdade era Saturno e vice-versa ${ }^{31}$.

Outro ponto é com relação a quantidade de variações. Na sua Tese XXIV diz que não deve haver excessos e faltas juntos, todavia faz esta associação em júpiter do qual parece contraditório. Além disso fala de 5 variações mais cita 6 (3 simples, duas duplas e um trio). Estas observações também são notadas por Brackenridge e Rossi, no qual também entendemos que Júpiter só tem uma variável simples (aquecimento moderado e umidificação moderada) logo as variações seriam: três simples e duas duplas confirmando as cinco variações escritas anteriormente ${ }^{32}$.

Como escreve Field, as discussões das características dos planetas são explicitamente baseadas nas discussões de Aristóteles sobre os pares de qualidades opostas na Metafísica, contudo, aponta modificações que faz para seus próprios propósitos. Também devemos ressaltar que "Kepler não está, no entanto, disposto a considerar esse arquétipo combinatório como necessariamente fundamental, e acrescenta que 'outras causas podem ter sido envolvidas também" ${ }^{\prime \prime 3}$.

\section{O papel da luz}

Rutkin destaca que alguns historiadores acreditam que Giovanni Pico Della Mirandola convenceu os astrólogos a parar a prática com sua publicação Disputationes adversus astrologiam divinatricem (1496) e outros ainda dizem que completou a destruição com o trabalho De revolutionibus orbium coelestium (1543) de Copérnico. Todavia, isto não é verdade, pois Kepler e Galileo Galilei ainda a praticavam ${ }^{34}$. Contudo, nos parece que tanto Pico quanto Copérnico têm papéis na história da queda. Essa hipótese se sustenta em uma visão expressada por Westman a partir de um estudo de Louis Valcke que não conseguimos acesso e que nos chama a atenção: a proposta inicial de Copérnico de reorganizar os planetas era, em parte, uma tentativa de defender os fundamentos teóricos da astronomia e da astrologia contra as críticas de Pico ${ }^{35}$. Westman também escreve sobre a ênfase da Pico na luz. Segundo outro estudo de Valcke que tivemos acesso, do ano de 1985를 , Pico retém a ideia neoplatônica de que a luz celestial é "de certa forma, o veículo ou, pelo menos, a imagem da ação divina no mundo" $\underline{\underline{37}}$.

Segundo Westman, Kepler, deve ter sido guiado pelo modelo de explicação de Aristóteles:

E em olhar para as propriedades de uma nova espécie de força motriz, ele deve ter sido orientado por modelo de uma boa explicação de Aristóteles. No caso do Sol, que incluiu considerações como o grau de perfeição (causa final); calor e luz, o material de que o Sol foi feito (causa material); A localização do Sol no centro do mundo (causa formal); e a sua capacidade para mover os planetas e gerar crescimento (causa eficiente) ${ }^{38}$.

Desse modo, todos esses atributos:

Iluminação, aquecimento, capacidade de movimento - podem ser encontrados no Sol, o corpo principal no universo. E, quando unido às periodicidades heliocêntricas, obtém-se uma única potência de movimento quase infinito no centro que se enfraqueceu de forma constante ao passar do mais próximo dos planetas aos mais distantes ${ }^{39}$.

Antes, acreditava-se que um astrônomo poderia apenas considerar a causa formal aristotélica de onde contempla a forma do movimento e não estaria este preocupado com a causa eficiente dos movimentos planetários e é aqui que está um dos grandes diferenciais dos estudos de Kepler. 


\section{Considerações finais}

Durante todo o estudo podemos observar a presença da luz, seja nos aspectos ou nas características dos planetas. Field escreve que 0

único legado da astrologia à filosofia natural séria parece ter sido a noção de força: a ação à distância (esse legado não foi, no entanto, transmitido por Kepler, que muito cedo rejeitou a força astrológica da Lua como uma explicação para as marés e apelou ao magnetismo para explicar o efeito do Sol sobre os planetas)ํํ.

Contudo, concordamos em parte com isso, com relação a palavra "único", pois, muito mais que a ideia da "força" foram as ricas discussões que provocou e que teve papel nas mudanças que ocorreram nas concepções de Universo e da própria ciência. Além disso, apesar de muito inicial, nosso estudo aponta para a importância da ênfase pela Luz que foi, várias vezes mencionada nas discussões sobre a astrologia seja a favor ou contra ela. Também não podemos afirmar até que ponto a astrologia em Kepler teve influência nas suas concepções de "força misteriosa" relacionada ao Sol. Neste primeiro estudo, podemos observar também a complexidade do pensamento de Kepler e a quantidade de possibilidades de estudo diante do tema, pois envolve uma gama bastante grande de relações entre seus contemporâneos e antecessores.

É interessante notar que na sua tese LXVIII ele escreve muitas ideias no qual faz comparações entre a alma e a luz e harmonia e "uma vez que o homem é um animal social, as almas se associarão mais estreitamente para propósitos públicos quando os raios dos planetas estiverem associados um ao outro, geometricamente, nos céus"ㄴ11, na perspectiva das almas diz na sua tese LXIX que a astrologia aponta inclinações destas, mas que parece loucura procurar maravilhas como alguns fazem com os calendários, pois o que se faz com as inclinações é com o livre arbítrio do homem que é a imagem e semelhança de Deus: "assim, se haverá paz ou guerra em alguma região em particular, é uma questão para o julgamento daqueles que são experientes na política, pois seu poder de predição não é menor do que 0 do astrólogo" $\underline{42}$, termina esta tese fazendo uma previsão sobre os dias seguintes que as almas dos soldados e dos comandantes estarão prontas para estratagemas, lutas, escaramuças e outros movimentos. Nas suas conclusões pede para que quem faz uso sério da sua filosofia e tenha objeções que escreva pra ele que a fim de obter a verdade e que se Deus o der habilidade responderá no prognóstico do ano seguinte, o fim do seu trabalho enfatiza orar a Cristo, mediador, para um ano feliz.

Até aqui vemos uma omissão dos signos do zodíaco, não porque resolvemos tirá-los, mas porque o próprio Kepler os rejeita o que gerou objeções ao tratado. Segundo Field essa rejeição não é baseada na realidade física das nossas visualizações aparentes das associações das estrelas vistas nas constelações, "mas sim, pela artificialidade das crenças tradicionais e descontinuidades acarretadas por elas"쓰. Isso, não totalmente, mas em parte tem a ver com seu copernicanismo em que ele reconhece que duas estrelas vistas não precisam estar próximas no espaço, discussão esta que podemos encontrar no capítulo The New Astronomy Against the New Metaphysics do livro From the Closed World to the Infinite Universe de Alexandre Koyré ${ }^{44}$. Tal fato esboçado priva a realidade física dos signos do zodíaco e como bem escreve Field, Kepler "de fato deu o passo seguinte de considerá-los como questões puramente da convenção humana" 45 .

Por fim, acreditamos que a astrologia em Kepler tem de fato papel fundamental em sua cosmologia. Esperamos ter contribuído para a percepção de que sua astrologia está longe de ser relacionada com bruxaria ou no sentido de previsões que não podemos escapar. Para nós do século XXI, um tanto difícil de ser compreendida, mas talvez um tema para dialogar com a sociedade, no que diz respeito as reflexões sobre as concepções do saber ao longo da história. 


\section{Notas e referências bibliográficas}

Luana Paula Goulart de Menezes é pós-graduanda na Universidade Estadual de Maringá. E-mail: lluanagoulart@gmail.com.

Michel Corci Batista é professor na Universidade Tecnológica Federal do Paraná, campus de Campo Mourão, e orientador no Programa de Pós-Graduação em Educação para a Ciência e a Matemática da Universidade Estadual de Maringá. E-mail: profcorci@gmail.com.

Daniel Gardelli é professor na Universidade Estadual de Maringá. E-mail: dgardelli2@uem.br.

1 PINHEIRO, Marcus Reis Pinheiro; MACHADO, Cristina de Amorim. Tradução comentada dos três primeiros Capítulos de Tetrabiblos de Ptolomeu. Cadernos de História e Filosofia da Ciência, v. 1, n. 2, 2015. p. 305-307.

2 Idem, p. 306-307.

3 THAGARD, Paul. R. Why Astrology is a Pseudoscience. PSA: Proceedings of the Biennial Meeting of the Philosophy of Science Association, v. 1, 1978. p. 224. Disponível em http://www.jstor.org/stable/192639. Acesso em 01 jun. 2019.

$4 \quad$ Idem, p. 223

5 RUTKIN, D. H. Astrology. In: DASTON. Lorraine e PARK. Katherine (Orgs.). The Cambridge History of Science. Vol. 3: Early Modern Science, Cambridge: Cambridge University Press, 2006, p. 541-542.

6 FIELD, J. V. A Lutheran Astrologer: Johannes Kepler. Archive for the History of Exact Sciences, v. 31, p. 189-272, 1984.

7 Idem, p. 190

8 Quadrivium é o conjunto de quatro ramos (Aritmética, Geometria, Música e Astronomia) orientados pela matemática e que em conjunto com o Trivium (Gramática, Lógica ou Dialética e Retórica) constituíam a componente basilar das sete artes liberais.

9 MOURÃO, R. R. F. Kepler: a descoberta das leis do movimento planetário. São Paulo: Odysseus Editora, 2ª ed., 2008, p. 41.

10 BONER, P. J. Soul-Searching with Kepler: An Analysis of Anima in His Astrology. Journal for the History of Astronomy, v. 36, n. 1, 2005. p. 7.

11 Idem, p. 7.

12 KEPLER, J. Gesammelte Werke: Manuscripta Astrologica, Manuscripta Pneumatica, bearbeitet von Friederike Boockmann, Daniel A. Di Liscia, unter mitwirkung von Daniel von Matuschka, Hans Wieland. München, vol. 21, 2.2. 2009.

13 Quod nativitates et Calendarias interdum scribo, ea me Christe molestissima mihi servitus est, sed necessaria, ne scilicet ad breve tempus liber, post turpius serviam. Itaque ut salarium annuum, ut titulum et locum defendam, obsecundandum est imperitae curiositatj. Übersetzung von Max Caspar und Walter Dyck: Johannes Kepler in seinen Briefen. Bd. 1. München und Berlin 1930, S. 120, apud KEPLER, 2009, p. 583.

14 KEPLER, J. Gesammelte Werke, Kleinere Schriften 1602/1611 Dioptrice, Unter der leitung von walther von dyck, und max caspar. München, vol. 4. 1941.

15 Das ist, Warnung an etliche Theologos, Medicos vnd Philosophos, sonderlich D. Philippum Feselium, daß sie bey billicher Verwerffung der Sternguckerischen Aberglauben nicht das Kindt mit dem Badt außschütten, vnd hiermit ihrer Profession unwissendt zuwider handeln (Kepler, 1602/1611, v.4, p.148).

16 PINHEIRO E MACHADO, op. cit., 2015, p. 312-313.

17 BONER, op. cit. 2005, p. 11.

18 Idem

19 Idem

20 Idem, p. 12

210 livro mencionado será Harmonices Mundi Libri V, veja nota 47 de FIELD, op. cit., 1984, p. 250.

22 FIELD, op. cit., 1984, p. 258-259

23 Do latim archetypus: são ideias e formas da mente de Deus que são expressas por meio da geometria na natureza.

24 BONER, P. J. Kepler's Cosmological Synthesis: Astrology, Mechnaism and the Soul. Boston: Brill, 2013, p. 56-57.

25 BRACKENRIDGE, J. B. Kepler, elliptical orbits, and celestial circularity: A study in the persistence of metaphysical commitment. Annals of Science, v. 39 , n. 3, 1982, p. 265-295.

26 FIELD, op. cit., 1984, p. 239.

27 Idem, p. 241-242.

28 Idem, p. 240

29 BRACKENRIDGE, J.; ROSSI, M. Johannes Kepler's on the More Certain Fundamentals of Astrology (Prague, 1601). Proceedings of the American Philosophical Society, v. 123, n. 2, 1979, p. 85-116.

30 PTOLOMEU, C. Le previsioni astrologiche (Tetrabiblos). Tradução de Simonetta Feraboli. Fondazione Lorenzo Valla/Arnoldo Mondadori Editore, $4^{\mathrm{a}}$ ed., 1998 , p.33-35.

31 Veja nota 17 de KEPLER, op. cit., v.4, 1941, p. 486.

32 BRACKENRIDGE; ROSSI, op. cit., 1979, p. 109-111

33 FIELD, op. cit., 1984, p. 197.

34 RUTKIN, op. cit., 2006, 541-542.

35 WESTMAN, R. S. Kepler's early physical-astrological problematic. Journal for the History of Astronomy, 2001, p. 227-236. 
VALCKE, L. Des Conclusiones aux Disputationes: numérologie et mathématiques chez Jean Pic de la Mirandole. Laval théologique et philosophique, v. 41 , n. 1, 1985, p. 43-56.

37

VALCKE, op. cit., 1985, p. 50.

38 WESTMAN, op. cit. 2001, p. 227-228.

39 Idem, p. 228.

$40 \quad$ FIELD, op. cit., 1984, p. 224.

$41 \quad$ Idem, p. 265.

42 Idem, p. 190.

43 Idem.

44 Idem, p. 199.

45 KOYRÉ, Alexandre. From the Closed World to the Infinite Universe. Baltimore: The Johns Hopkins University Press, 1957.

[Artigo recebido em Fevereiro de 2020. Aceito para publicação em Dezembro de 2020] 